Article

\title{
Cellulose Nanocrystal Reinforced Chitosan Based UV Barrier Composite Films for Sustainable Packaging
}

\author{
Mithilesh Yadav ${ }^{1,2, *}$, Kartik Behera ${ }^{1}$, Yen-Hsiang Chang ${ }^{3,4}$ and Fang-Chyou Chiu 1,3,* \\ 1 Department of Chemical and Materials Engineering, Chang Gung University, Taoyuan 333, Taiwan; \\ b.kartik1991@gmail.com \\ 2 Department of Chemistry, Prof. Rajendra Singh Institute of Physical Sciences for Study and Research, \\ V.B.S Purvanchal University Jaunpur, Siddikpur U.P. 222002, India \\ 3 Department of General Dentistry, Chang Gung Memorial Hospital, Taoyuan 333, Taiwan; \\ cyh4714@hotmail.com \\ 4 Graduate Institute of Dental and Craniofacial Science, Chang Gung University, Taoyuan 333, Taiwan \\ * Correspondence: dryadavin@gmail.com (M.Y.); maxson@mail.cgu.edu.tw (F.-C.C.); \\ Tel.: +91-8738045471 (M.Y.); +886-953678628 (F.-C.C.)
}

Received: 15 December 2019; Accepted: 10 January 2020; Published: 13 January 2020

\begin{abstract}
In this study, green composite films based on cellulose nanocrystal/chitosan (CNC/CS) were fabricated by solution casting. FTIR, XRD, SEM, and TEM characterizations were conducted to determine the structure and morphology of the prepared films. The addition of only $4 \mathrm{wt} . \% \mathrm{CNC}$ in the CS film improved the tensile strength and Young's modulus by up to $39 \%$ and $78 \%$, respectively. Depending on CNC content, the moisture absorption decreased by $34.1-24.2 \%$ and the water solubility decreased by $35.7-26.5 \%$ for the composite films compared with neat CS film. The water vapor permeation decreased from $3.83 \times 10^{-11}$ to $2.41 \times 10^{-11} \mathrm{gm}^{-1} \mathrm{~s}^{-1} \mathrm{~Pa}^{-1}$ in the CS-based films loaded with (0-8 wt.\%) CNC. The water and UV barrier properties of the composite films showed better performance than those of neat CS film. Results suggested that CNC/CS nanocomposite films can be used as a sustainable packaging material in the food industry.
\end{abstract}

Keywords: nanocomposite; chitosan; cellulose nanocrystal; UV barrier; mechanical properties

\section{Introduction}

Petrochemical-based polymeric materials are extensively used in various applications ranging from packaging materials to aircraft components. The broad application of these materials had led to severe environmental challenges due to improper disposal in the environment. In this regard, researchers have focused on biodegradable sustainable packaging materials from scientific and technical sectors [1-3]. Hence, bio-based packaging materials based on polysaccharides, proteins, and lipids are increasingly used $[4,5]$. However, the inferior mechanical and poor barrier properties of natural polymers often hinder their application in food packaging. Reinforcing nanofillers are incorporated into biopolymer formulations to effectively enhance their thermal and physio-chemical properties and fabricate high-performance polymer nanocomposite films [6-8]. Nanocomposite films can also serve as water and UV light barriers to improve the shelf-life and quality of preserved food products [9].

Chitosan (CS) is a natural cationic polysaccharide containing numerous reactive amino groups ( $\beta$-1,4-linked glucosamine and $N$-acetylglucosamine) that can participate in several chemical reactions [10,11]. CS is yielded by the partial deacetylation (to varying degrees) of chitin, which is the second most abundant naturally occurring polysaccharide next to cellulose. CS is very useful in various fields, such as food, agriculture, and wastewater treatment [12]. CS can also be applied to prevent the dehydration of meat, which is the most important diet to sustain human life [13]. 
CS has been recently exploited in biomedical applications owing to its distinctive properties, namely, biocompatibility, biodegradability, mucoadhesion, excellent film forming properties, nontoxicity, and broad antimicrobial activity against fungi and bacteria [14-21]. Thus, CS is a potential candidate for manufacture of edible films for a large set of applications in pharmacy and packaging industries. Nevertheless, the poor mechanical and barrier properties of CS must be enhanced by combining it with appropriate reinforcement fillers [6,15]. Zhang et al. [22] reported that the addition of $\mathrm{TiO}_{2}$ nanoparticles into CS film enhanced the mechanical, thermal, and UV-barrier properties of the neat CS film. Barra et al. [6] evaluated the mechanical properties, electrical conductivity, and antioxidant activity of CS bio-nanocomposite films with and without reduced graphene oxide (rGO).

Over the past decade, natural fillers have been widely applied as reinforcing materials to replace synthetic or inorganic fillers for polymer matrices to obtain bio-based nanocomposites. Given the structural (high aspect ratio, dimension, and alignment), mechanical, and thermal properties of cellulose nanocrystals(CNC), their incorporation into polymers opens a new avenue for achieving high-performance polymer nanocomposites [23]. Cellulose is the most abundant renewable biopolymer on earth and is commonly found in the primary cell wall of green plants [24,25]. Needle-shaped crystalline CNC can be obtained through acid hydrolysis of cellulose fibers. CNC normally possesses an average length of $100 \mathrm{~nm}-2 \mu \mathrm{m}$ and a diameter of 5-20 nm [26]. Moreover, the flocculation of CNC depends on the type of hydrolysis [27]. Sometime, isolated CNC does not flocculate with water because of their electrostatic repulsion characteristic on the surface. Thus, CNC suspensions are stable for several months.

CNC has been successfully exposed to reinforce polymers due to the establishment of percolating network that connects well-distributed $\mathrm{CNC}$ by hydrogen bonds within polymer matrices. Polymer matrix incorporated with CNC reinforcing filler exhibits superior performance, such as barrier, thermal, and mechanical properties, allowing the manufacturing of next-generation polymer-based nanocomposites [5,28-30]. CNC has been widely blended with CS because of the excellent merged properties of CS (biocompatibility, antimicrobial, and tear-resistance) and CNC (good barrier, thermal, mechanical, and high aspect ratio) in CNC/CS nanocomposites. Khan et al. [31] examined the effect of CNC loading on the barrier and mechanical properties of CS-based nanocomposite films; they found that the incorporation of $5 \mathrm{wt} . \% \mathrm{CNC}$ in CS enhanced the tensile properties of the biodegradable composite films. Salari et al. [5] recently investigated the effect of adding bacterial CNC and silver nanoparticles on the thermal, mechanical, and antimicrobial activity of CS-based composite films. Mujtaba et al. [30] studied the CNC/CS-based composite films and reported that adding $20 \mathrm{wt} . \% \mathrm{CNC}$ enhanced the mechanical properties of the prepared film. Ma et al. [29] examined CS composites reinforced with modified CNC as cellulose spheres for food packaging applications; these composites exhibited reduced water vapor permeation (WVP) and improved thermal/mechanical properties.

Among known CS-based composites, CNC/CS nanocomposite is widely investigated [31-35] over the past years. To the best of our knowledge, the UV-barrier properties of CNC/CS bionanocomposites have not been investigated yet. The current study aims to determine the influence of modified CNC on the physicochemical properties of biodegradable/CS-based nanocomposite films intended for use as edible food packaging with improved UV barrier and mechanical properties. The structure, morphology, and thermal/mechanical properties of the fabricated films were evaluated and compared. The water solubility, water absorbency, photo-barrier, and biodegradability properties were also highlighted in this work. Results are predicted to open up a green avenue toward designing and fabricating fully bio-based and high-barrier materials for sustainable food packaging applications. 


\section{Materials and Methods}

\subsection{Chemical and Reagents}

CS (molecular weight $=350,000 \mathrm{gmol}^{-1}$; the deacetylation degree $=90 \%$ ) was purchased from Sigma Aldrich (Tapei, Taiwan). Cellulose microcrystal (CMC) (size $5 \mu \mathrm{m}$ ) was supplied by JRS, Paris, France. Sulfuric acid and glacial acetic acid were obtained from J.T. Baker, Phillipsburg, NJ, USA. Phosphotungstic acid (staining agent) was used as received from Sigma Aldrich (Taoyuan, Taiwan). Deionized water (DIW) was used in the entire study.

\subsection{Fabrication of CNC from $\mathrm{CMC}$}

Sulfuric acid hydrolysis was adopted using a previously reported procedure to extract CNC from a commercial CMC [7]. Oven-dried CMC powder (ca. $3 \mathrm{~g}$, at $70{ }^{\circ} \mathrm{C}$ for $12 \mathrm{~h}$ ) was hydrolyzed with sulfuric acid solution ( $20 \mathrm{~mL}, 64 \mathrm{wt} . \%)$ at $48^{\circ} \mathrm{C}$ for $1 \mathrm{~h}$ with continuous mechanical stirring. After hydrolysis, the resultant suspension was poured into $200 \mathrm{~mL}$ of cold DIW $\left(<5^{\circ} \mathrm{C}\right)$ to stop the reaction. The reaction was further continued for $1 \mathrm{~h}$ with continuous mechanical stirring and terminated by adding $200 \mathrm{~mL}$ of cold DIW. The supernatant was eliminated after the completion of the reaction. The decanting step was repeated at least twice for $24 \mathrm{~h}$. The sediment obtained after removing the supernatant was collected and washed by centrifugation at 10,000 rpm for $5 \mathrm{~min}$ at room temperature. Centrifugation was performed two to three times before the product was dialyzed in millipore water. The millipore water was frequently replaced until $\mathrm{pH}$ of 7 was obtained. The suspension was subjected to ultra-sonication (DELTA Ultrasonic Cleaner DC300H, Delta Electronics, Taoyuan, Taiwan) for $1 \mathrm{~h}$ at an operating frequency of $40 \mathrm{kHz}$ and power dissipation of $300 \mathrm{~W}$ to avoid the aggregation of unfractionated cellulose nanoparticles. The product was freeze dried and called CNC. With help of Image J software (LOCI, University of Wisconsin, Madison, WI, USA; applying on TEM), the length and diameter of CNC was found 100-500 nm and 5-30 nm, respectively. The obtained CNC yield was ca. 65\%.

\subsection{Synthesis of CNC/CS Nanocomposite Films}

CS nanocomposites reinforced with CNC were prepared by solution casting. CS solution (1\% w/v) was prepared by dissolving CS flakes into $2 \%(\mathrm{v} / \mathrm{v})$ glacial acetic aqueous solution and mechanically stirred for 5-7 h. The prepared and formulated CNC $(2,4,6$, and $8 \mathrm{wt}$. \%) was dispersed in $50 \mathrm{~mL}$ of DIW, magnetically stirred for $15 \mathrm{~min}$, and sonicated in an ultrasonic bath for $30 \mathrm{~min}$. The obtained CNC water suspension was added to the CS solution and stirred for $1 \mathrm{~h}$ at room temperature. The resulting dispersion was degassed under vacuum suction, casted on a petri dish, and dried in an oven at $50{ }^{\circ} \mathrm{C}$ for 12-15 h until the solvent was completely evaporated and a self-standing film was attained. The dried CNC/CS nanocomposite films with 0, 2, 4, 6 and $8 \mathrm{wt}$ \% loading of CNC were named as CS0, CS2, CS4, CS6, and CS8, respectively. The procedure regarding the fabrication of CNC/CS films is presented in Figure 1. 


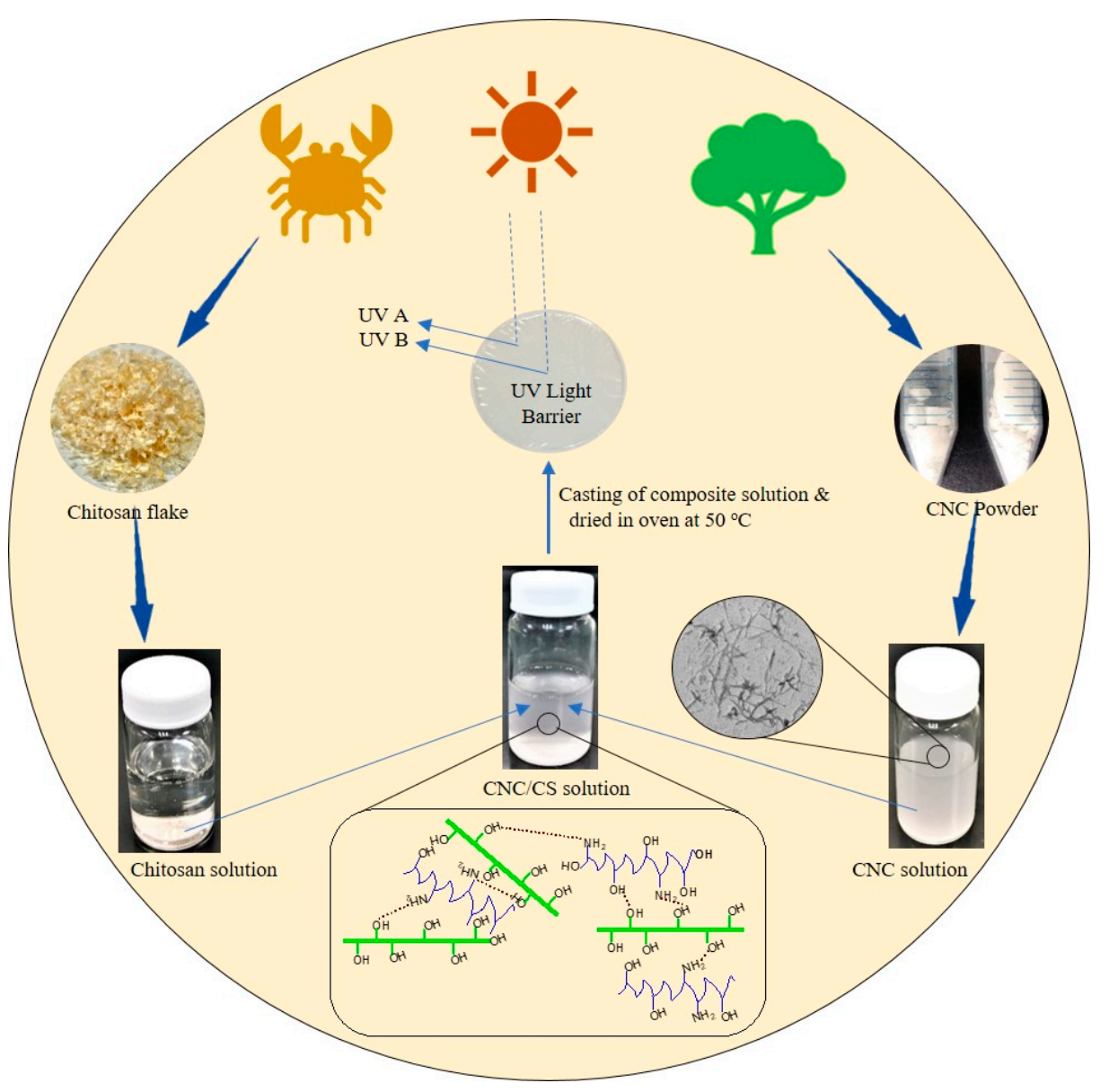

Figure 1. Schematic of preparing cellulose nanocrystal/chitosan (CNC/CS) nanocomposite films.

\subsection{Conditioning}

Prior to running other tests, prepared films were conditioned at $25 \pm 1{ }^{\circ} \mathrm{C}$ and $65 \% \pm 2 \% \mathrm{RH}$ for $48 \mathrm{~h}$ in a desiccator. This thermal condition was in the acceptable range of ISO 7730. All the studies were done in triplicate for confirming the reproducibility.

\subsection{Thickness}

The thickness of the films $(0.020-0.021 \mathrm{~mm})$ was measured using hand-held Tec lock dial thickness gauge (SM-112, TECLOCK Co., Ltd., Tokyo, Japan) and six random measurements for each film were taken.

\subsection{Fourier-Transform Infrared Spectroscopy (FTIR)}

Fourier-transform infrared spectrometer (TENSOR 27, Bruker, Karlsruhe, Germany) was used for FTIR of samples. Spectra were recorded at wave numbers ranging from $500-4000 \mathrm{~cm}^{-1}$.

\subsection{Transmission Electron Microscopy (TEM)}

The method of sample preparation for TEM was followed by recently published paper [36]. The images of CNC were observed by a JEOL (JEM-1230 electron microscope, JEOL Ltd., Tokyo, Japan) with an accelerating voltage of $200 \mathrm{kV}$.

\subsection{Scanning Electron Microscopy (SEM)}

The dispersion of CNC in the chitosan matrix and the particle sizes were observed with a field emission scanning electron microscopy (FESEM; SEM; Jeol JSM-7500F, JEOL Ltd., Tokyo, Japan) 
operated with an acceleration voltage of $18 \mathrm{kV}$. All the specimens were sputter-coated with gold before examination.

\subsection{Optical Microscopy (OM)}

To delineate the morphology and dispersion status of CNC within the matrix phase, OM (Olympus BX-50, Olympus Corporation, Tokyo, Japan) was performed at room temperature.

\subsection{X-ray Diffraction (XRD)}

XRD measurements were performed by an X-ray diffractometer (D2, Bruker, Karlsruhe, Germany) with $\mathrm{CuK}_{\alpha}$ radiation source $(\lambda=0.154 \mathrm{~nm})$ operating at $40 \mathrm{kV}$ and $40 \mathrm{~mA}$. A scattered radiation was recorded at an ambient temperature in the $2 \theta$ range of $10-40^{\circ}$ using a step interval of $0.02^{\circ}$ and scan speed of $1 \% \mathrm{~min}$. The degree of crystallinity was measured by Segal's empirical method with the following equation [37]:

$$
\mathrm{CI}(\%)=\frac{\mathrm{I}_{002}-\mathrm{I}_{\mathrm{am}}}{\mathrm{I}_{002}} \times 100,
$$

where $\mathrm{I}_{002}$ is the intensity value for the crystalline cellulose $\left(2 \theta=22.5^{\circ}\right)$ and $\mathrm{I}_{\mathrm{am}}$ is the intensity value for the amorphous cellulose $\left(2 \theta=16.3^{\circ}\right)$.

\subsection{Thermogravimetric Analysis (TGA)}

A thermogravimetric analyzer (TA Q50, TA Instrument, New Castle, DE, USA) was carried out to analyze the thermal stability of the films. The measurement were perused with a temperature range from room temperature to $700^{\circ} \mathrm{C}$ at heating rate of $10^{\circ} \mathrm{C} / \mathrm{min}$ under both nitrogen and air atmospheres.

\subsection{Opacity and UV Visibility}

The opacity of prepared films was determined by measuring the film absorbance at $600 \mathrm{~nm}$ using UV spectrometer (JASCO, V-650, Tokyo, Japan) and calculating by the equation:

$$
\text { Opacity }=\mathrm{Abs}_{600} / \mathrm{d}
$$

where, $\mathrm{Abs}_{600}$ is the value of absorbance at $600 \mathrm{~nm}$ and $\mathrm{d}$ is the film thickness (mm).

\subsection{Water Absorbency (WA) of the Films}

Water absorbency (WA) of prepared film is examined in terms of percentage swelling ratio. The details about the procedure and condition for WA were followed by our recently published paper [7].

$$
\text { Swelling Ratio }(\%)=\mathrm{P}_{\mathrm{s}}=\frac{\mathrm{W}_{\mathrm{s}}-\mathrm{W}_{\mathrm{d}}}{\mathrm{W}_{\mathrm{d}}} \times 100,
$$

where, $W_{d}$ and $W_{s}$ is the weight of dry and swollen samples, respectively.

\subsection{Equilibrium Moisture Content (EMC)}

The equilibrium moisture content (EMC) of the prepared films was calculated by measuring the weight loss of films pieces $\left(2 \times 2 \mathrm{~cm}^{2}\right)$ upon dried in a hot oven at $102 \pm 2{ }^{\circ} \mathrm{C}$ to reach the equilibrium weight $\left(\mathrm{W}_{\infty}\right)$ with its initial (dry) weight $\left(\mathrm{W}_{\mathrm{o}}\right)$, as follows:

$$
\mathrm{EMC}=\frac{\mathrm{W}_{\infty}-\mathrm{W}_{\mathrm{o}}}{\mathrm{W}_{\mathrm{o}}} \times 100 .
$$

\subsection{Film Water Solubility (FWS)}

FWS was deliberated by recently published paper [7,38]. The samples $\left(2 \times 2 \mathrm{~cm}^{2}\right)$ were dried at $27^{\circ} \mathrm{C}$ for $24 \mathrm{~h}$ to determine the initial dry weight $\left(\mathrm{W}_{\mathrm{i}}\right)$. Then, the film were immersed in $20 \mathrm{~mL}$ 
of deionized water with mild shaking, removed, and then dried at $40{ }^{\circ} \mathrm{C}$ for $24 \mathrm{~h}$ to determine the undissolved final dry weight $\left(\mathrm{W}_{\mathrm{f}}\right)$. FWS was calculated using the following equation [39]:

$$
\mathrm{FWS}=\frac{\mathrm{W}_{\mathrm{i}}-\mathrm{W}_{\mathrm{f}}}{\mathrm{W}_{\mathrm{i}}} \times 100
$$

\subsection{Contact Angle}

A Drop Shape Analysis System (model DIGIDROP GBX instrument, GBX, Romans sur Isere, France) was operated for contact angle measurements. The hydrophilic nature of the prepared films was evaluated by deionized water.

\subsection{Water Vapor Permeation (WVP)}

According to ASTM-E96/E96-05 Standard method, the WVP of CS nanocomposite films was studied. The details about the procedure for measuring WVP of samples was followed by Yadav et al. [7]. In each test petri dish, $20 \mathrm{~mL}$ of distilled water were added, leaving a distance of approximately $1 \mathrm{~cm}$ between the water surface and the film. The film samples were sealed to the dish mouth by a water-resistant sealant. The petri dishes were conditioned in a humid chamber (Giant Force, Tapei, Taiwan) at $25^{\circ} \mathrm{C}$ to ensure $65 \% \mathrm{RH}$, and weight was noted a certain interval of time. The provided Equation (6) was used to calculate the WVP data.

$$
\text { WVP }\left(\mathrm{g} \mathrm{m}^{-1} \mathrm{~s}^{-1} \mathrm{~Pa}^{-1}\right)=(\mathrm{w} / \mathrm{t}) \gamma(\mathrm{A})^{-1}(\Delta \mathrm{p})^{-1} \text {. }
$$

where, $\mathrm{w}$ is the weight loss of the Petri dishes (g), $\gamma$ is the film thickness (m), A is the cross-section area of the film $\left(\mathrm{m}^{2}\right), \mathrm{t}$ is the time (s), and $\Delta \mathrm{p}$ is the vapor pressure difference.

\subsection{Mechanical Properties}

The mechanical properties of the films (according to ASTM D638) were performed using a Gotech AI-3000 system (Gotech Testing Machines Inc., Taichung, Taiwan) at room temperature $\left(24 \pm 2{ }^{\circ} \mathrm{C}\right)$. Crosshead speed was set at $10 \mathrm{~mm} / \mathrm{min}$ for all the specimens. The pull tests of the films in terms of tensile strength and elongation at break (\%) was calculated by published papers [36].

\subsection{Soil Burial Test}

Soil burial tests for film biodegradation characteristics were conducted according to previously reported method described by Martucci et al. [40]. The samples were cut into rectangular parts $(1 \mathrm{~cm} \times$ $1 \mathrm{~cm} \times 0.002 \mathrm{~cm})$ and dried in an oven at $100{ }^{\circ} \mathrm{C}$ for $5 \mathrm{~h}$ prior to weighed $\left(\mathrm{W}_{\mathrm{i}}\right)$. A total amount $(30 \mathrm{~g})$ of garden soil was poured into a plastic pot up to a thickness of approximately $1 \mathrm{~cm}$. Then, the films were buried under soil at a depth of $0.5 \mathrm{~cm}$ from the soil surface. The assay was performed at $25^{\circ} \mathrm{C}$ and $30 \%$ RH by using a humid chamber (Giant Force, Tapei, Taiwan). Samples were taken from the soil at different times and cleaned carefully with tissue paper. Subsequently, the samples were dried in an oven at $105^{\circ} \mathrm{C}$ for $6 \mathrm{~h}$ and weighed $\left(\mathrm{W}_{\mathrm{t}}\right)$ to determine the percentage of weight loss using the following equation:

$$
\text { Weight } \operatorname{loss}(\%)=\frac{\mathrm{W}_{\mathrm{i}}-\mathrm{W}_{\mathrm{t}}}{\mathrm{W}_{\mathrm{i}}} \times 100
$$

\section{Results}

\subsection{FTIR}

The FTIR spectra of CS, CMC, CNC, and CS4 are presented in Figure 2. The FTIR spectra of $\mathrm{CNC}$ confirmed that a sharp peak at $3350 \mathrm{~cm}^{-1}$ was found due to the $\mathrm{OH}$ vibrations in hydrogen bonds [41]. The absorption bands between 2800 and $3000 \mathrm{~cm}^{-1}$ originated from $\mathrm{C}-\mathrm{H}$ stretching and bending vibrations [42]. The other absorption bands were assigned at $567(\mathrm{O}-\mathrm{H}$ out of plane bending 
vibrations), 1058 (C-O stretching at $\mathrm{C}-3$ position), and $1163 \mathrm{~cm}^{-1}$ (C-O-C stretching motion) [43]. Aside from these peaks, the CNC showed two more peaks at 1645 and $1240 \mathrm{~cm}^{-1}$, confirming the acidification of the CMC was successfully performed [44]. Furthermore, the abundant oxygen functional groups rendered the CNC hydrophilic, which improved their solubility in water. When CNC was added to $\mathrm{CS}$, the peaks at $3392-3405$ ( $\mathrm{NH}_{2}$ stretching vibration), 1539-1542, 1341-1335, 1029-1032, and 1063-1072 $\mathrm{cm}^{-1}$ sharpened with increased intensity, indicating that CNC interacted with CS through hydrogen bonds [23]. Furthermore, the appearance of two peaks at 2916 (symmetric $\mathrm{C}-\mathrm{H}$ vibration) and $2856 \mathrm{~cm}^{-1}$ (symmetric and asymmetric $\mathrm{C}-\mathrm{H}$ vibration) in CNC/CS confirmed the bonding of CS and CNC.

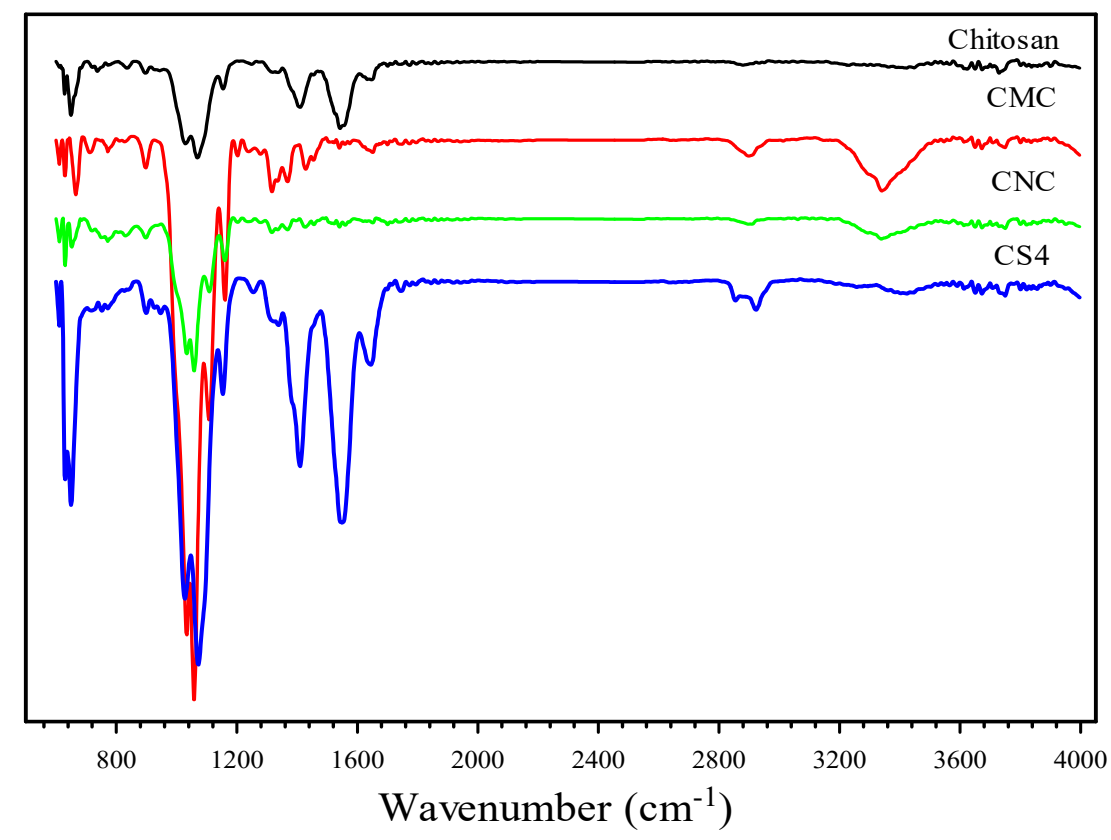

Figure 2. FTIR of CS, CMC, CNC, and CS4 samples.

\section{2. $X R D$}

The physical interaction between biopolymer and nanofiller can be understood based on degree of crystallinity. XRD analysis was conducted within the $2 \theta$ range of $10-40^{\circ}$ on CMC, CNC, CS0, CS2, CS4, CS6, and CS8 samples. As shown in Figure 3, CMC showed four crystalline peaks at $15.3^{\circ}, 16.5^{\circ}$, $22.6^{\circ}$, and $34.7^{\circ}$. However, after acid treatment of CMC, CNC exhibited peaks at $15.6^{\circ}(101), 16.4^{\circ}$ $(101), 23.0^{\circ}(200)$, and $34.6^{\circ}(400)[7,45]$. The calculated crystallinity index (CI) values of CMC and CNC were ca. $40 \%$ and $50 \%$, respectively, suggesting that structural change by the acid treatment of CMC was responsible for the increased CI of CNC. For CS, two main peaks appeared at $10^{\circ}(002)$ and $20^{\circ}(101)$ due to its crystalline nature. The CI of chitosan film was found $35 \%$, which was agreed with previously published paper [46]. With the addition of CNC to the CS matrix, the mechanical and physical properties of the films were changed due to the crystalline morphology, crystal forms, and crystallite size of CNC [47]. In the case of blends the diffraction peaks for both chitosan and $\mathrm{CNC}$ were sifted to a higher value with increasing $\mathrm{CNC}$ content, thus the peaks from $10^{\circ}$ was shifted to $12.05^{\circ}, 15.6^{\circ}$ at $15.7^{\circ}, 16.4^{\circ}$ at $16.7^{\circ}, 20^{\circ}$ is combined with that from $23^{\circ}$ of $\mathrm{CNC}$ and is shifted at $22.75^{\circ}$, and the signal at $34.6^{\circ}$ at $34.65^{\circ}$. These shifting induce an increasing in the lattice distance with increasing the $\mathrm{CNC}$ content. The incorporation of the rigid molecules of $\mathrm{CNC}$ in the chitosan matrix induced an orientation of the polymeric molecules and favored the formation of hydrogen bonds between the polymeric chains. 


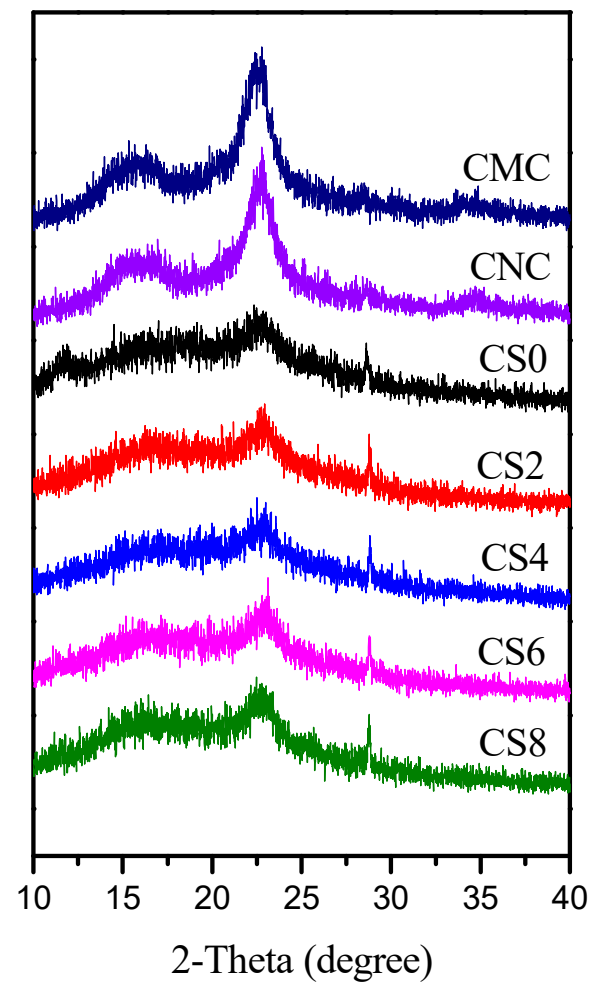

Figure 3. $\mathrm{XRD}$ of $\mathrm{CMC}, \mathrm{CNC} \mathrm{CS} 0, \mathrm{CS} 2, \mathrm{CS} 4, \mathrm{CS} 6$, and CS8 samples.

\subsection{Microstructure and Dispersibility of CNC}

The FESEM image of aggregated needle-shaped CNCs in bundle form is presented in Figure 4a. The bundles of CNC were easily dispersed in water due to their modified nature. As shown in the TEM image of Figure $4 b$, the length and width of the obtained needles were 100-500 and 5-30 nm, respectively. The optical microscope (OM) images of the CMC, CNC, CS0, CS2, CS4, CS6, and CS8 samples in dry form at $20 \times$ magnification are presented in Figure 5. The bundles of CMC and CNC are presented in Figure 5a,b, respectively. As predicted from Figure 5c, a smooth surface of CS0 film was observed. The surfaces of CS2 and CS4 revealed a uniform and dense arrangement due to the small size and homogeneous distribution of CNC in the films. However, CS films with high CNC content (cf. CS6 and CS8) had rough surfaces. Thus, a stiff break with a high loading of CNC is recommended. The cross-section micrographs of CS0 and CS4 are presented in Figure 4c,d. Figure 4d shows the increased smoothness of CS upon further loading of CNC, suggesting the effect of the distribution of CNC particles. The tensile fractured micrograph of CS0 and CS4 showed roughness due to the presence of broken fibers (Figure 4e,f). No phase separation was found, indicating good adhesion between the CS and the CNC. Structural studies confirmed that the incorporation of CNC into the CS matrix resulted in a homogeneous composite, in which the individual components are connected by hydrogen bonds [48]. Similar findings were reported by Garcia et al. [49] and Yadav et al. [7]. The uniform and homogeneous distribution of $\mathrm{CNC}$ in the nanocomposite film is responsible for the enhanced physico-mechanical properties of the CS based film. 

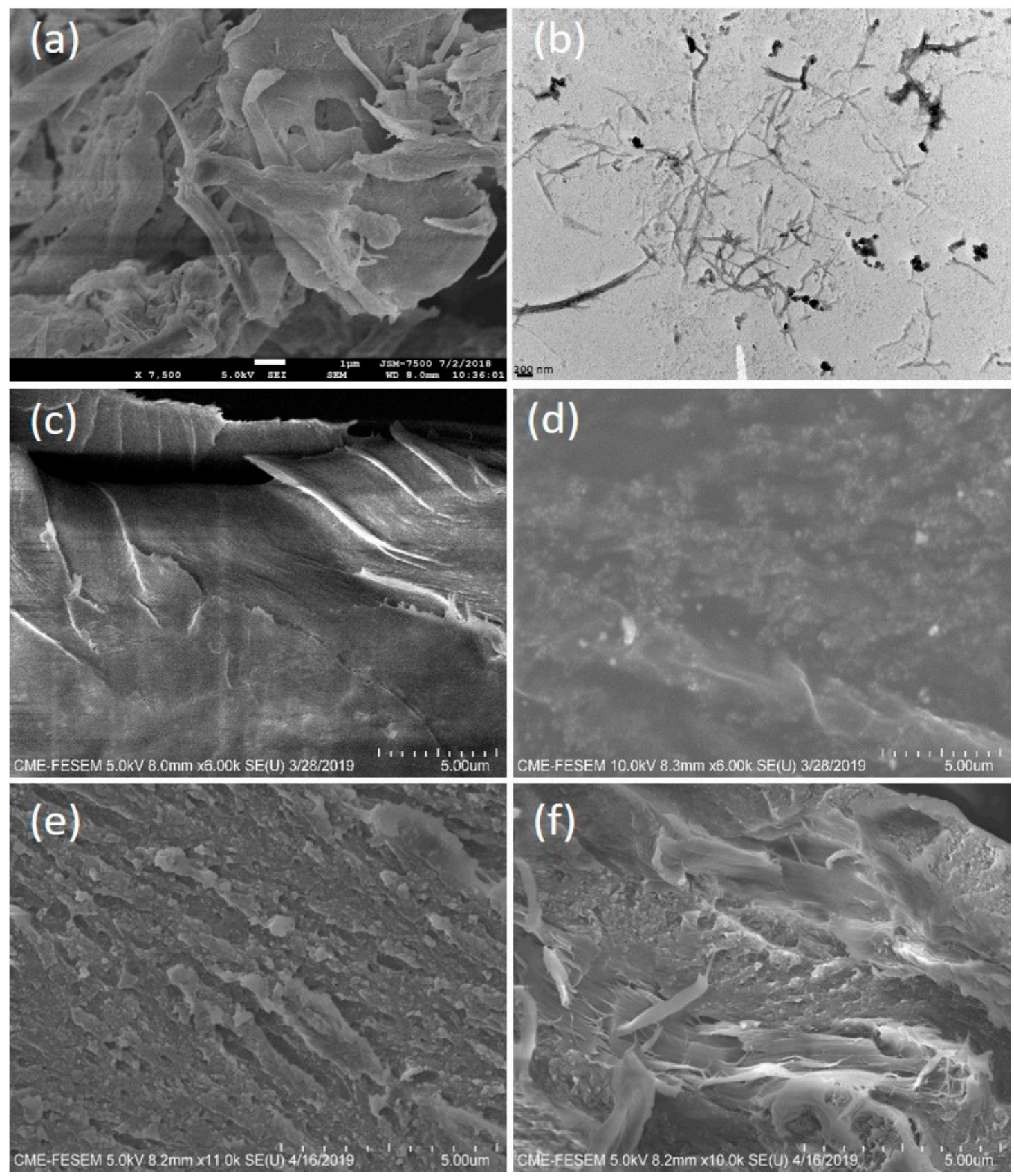

Figure 4. (a) Field emission scanning electron microscopy (FESEM) of CNC in powder form, (b) TEM image of water dispersed CNC, (c) FESEM cross-section image of CS0 films, (d) FESEM cross section image of CS4 film, (e) FESEM cross-section image of fractured CS0 films, and (f) FESEM cross-section image of fractured CS4 film. 

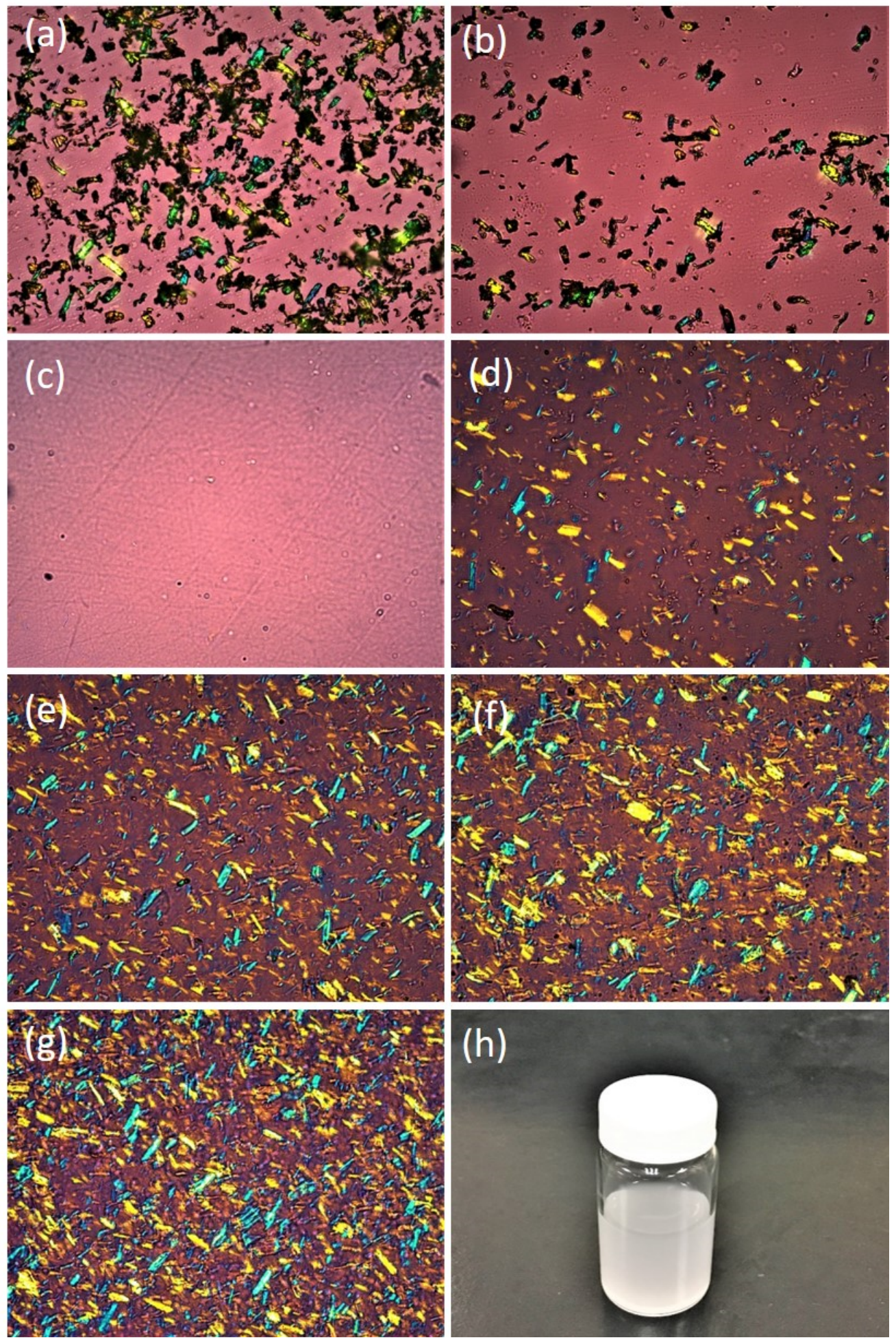

Figure 5. Optical microscope (OM) images of (a) CMC in powder form, (b) CNC in powder form, (c) CS0 film, (d) CS2 film, (e) CS4 film, (f) CS6 film, (g) CS8 film, and (h) digital image of water dispersed $\mathrm{CNC}$.

\subsection{Thermal Stability of Films}

Biomaterial-based packaging films are extensively used in the food industry due to their short processing time and high yield with low production cost. However, the temperatures reduce film stability due to degradation [50]. Therefore, the thermal behavior of the fabricated films must be 
evaluated. Here, TGA was performed to evaluate the effect of CNC on the degradation behavior of $\mathrm{CNC/CS}$ composite films (Figure 6). Figure 6a,b illustrates the TGA/DTGA curves of all of the samples scanned under nitrogen environment. As shown in Figure 6a, neat CMC and CNC exhibited similar decomposition curves. CNC possessed slightly higher degradation temperature than CMC. Two-staged degradations were observed during the thermal scanning of the samples. A small weight loss occurred in the first stage of degradation at ca. $100^{\circ} \mathrm{C}$, which could be attributed to the evaporation of absorbed water in the sample. The major weight loss in the second stage of degradation at $300-400{ }^{\circ} \mathrm{C}$ may be due to the concurrent cellulose degradation processes, such as dehydration, depolymerization, and decomposition of the glycosidic bonds of CMC/CNC [7].
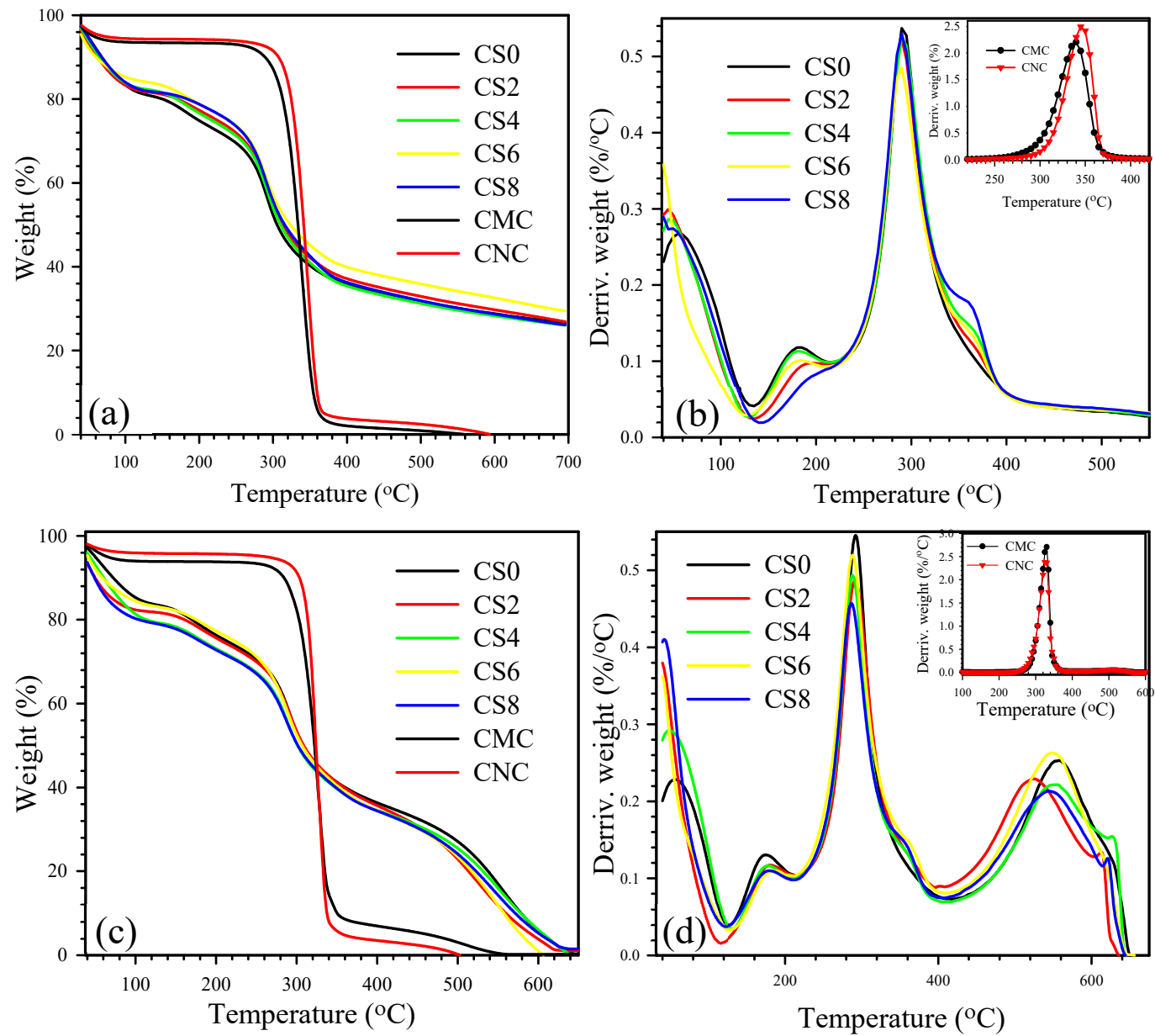

Figure 6. Thermal decomposition curves of CS0, CS2, CS4, CS6, CS8, CMC, and CNC: (a) and (b) $\mathrm{N}_{2}$ environment, and (c) and (d) air environment.

Neat CS and CNC/CS with different combined ratios showed multiple degradation curves. The composites showed slightly higher degradation curves than the neat CS. After CNC inclusion, the thermal stability of CNC-reinforced CS composite films showed marginal improvement due to interactions between CNC and CS matrix [51]. Figure $6 \mathrm{~b}$ depicts the derivative TGA (DTG) curves of the samples. Neat $C M C$ showed a lower peak temperature $\left(T_{\max }\right.$, temperature at maximum weight loss rate) than CNC, as illustrated in the inset of Figure 6b. The neat CS and CS with different weight ratios of $C N C$ exhibited three peak temperatures ( $\mathrm{T}_{\operatorname{maxI}}, \mathrm{T}_{\text {maxII }}$, and $\mathrm{T}_{\text {maxIII }}$ ). $\mathrm{T}_{\operatorname{maxI}}$ (first stage) occurred at the range of $40-100{ }^{\circ} \mathrm{C}$, which corresponds to a weight loss of ca. $14 \%$ and is attributed to the evaporation of residual acetic acid [52] and physical trapping of water and/or weakly hydrogen-bonded to CS molecules. The second stage ( $\mathrm{T}_{\text {maxII }}$ ) of weight loss at below $200{ }^{\circ} \mathrm{C}$ could be assigned to the initial degradation of the polymer and/or release of atypical, strongly hydrogen-bonded 
water. The predominant (final stage) thermal degradation peak occurred within $250-400{ }^{\circ} \mathrm{C}\left(\mathrm{T}_{\text {maxIII }}\right.$ at $292{ }^{\circ} \mathrm{C}$ ), during which a $48 \%$ decline of the CS mass was detected. This finding could be due to the depolymerization of CS chains and the decomposition of pyranose rings [53] through dehydration and deamination, followed by final ring-opening reaction [54].

TGA was also performed in air environment to evaluate the thermal oxidation behavior of CS and CNC/CS composite films (Figure 6). The degradation behavior of CS and CNC/CS under oxidized conditions was substantially different from that under nitrogen atmosphere. As shown in Figure $6 c$, the samples exhibited slightly lower degradation temperature than their corresponding nitrogen environment-scanned samples because of auto-oxidation [54]. The neat CNC exhibited higher degradation temperature at $50 \mathrm{wt} . \%$ loss compared with neat CMC. All of the CS samples (CS and CNC/CS) showed similar degradation behavior appeared within $200-350{ }^{\circ} \mathrm{C}$ with $57 \%$ weight loss occurring at almost $292{ }^{\circ} \mathrm{C}$ as observed in nitrogen. The main difference between nitrogenand air-atmosphere-scanned samples is the additional decomposition peak ( $\left.\mathrm{T}_{\text {maxIV }}\right)$ that occurred above $400{ }^{\circ} \mathrm{C}$, as depicted in Figure $6 \mathrm{~d}$. The strong exothermic effects in the presence of oxygen indicate the occurrence of efficient oxidation, followed by further decomposition of oxidized CS. These stages with high weight loss are attributed to very efficient chain scission with the formation of volatile degradation products [54]. All $\mathrm{T}_{\max }$ values and residue wt.\% of the samples scanned under nitrogen and air environments and temperatures at $50 \mathrm{wt} . \%$ loss $\left(\mathrm{T}_{\mathrm{d} 50}\right)$ are listed in Table S1. All of the composites films scanned under nitrogen and air environment exhibited $\mathrm{T}_{50 \%}$ values above $285^{\circ} \mathrm{C}$. Hence, these composite materials are regarded as stable at high temperatures and have potential as packaging materials.

\subsection{Water Absorbency of CNC/CS Film}

The water absorbency in terms of percentage swelling $\left(\mathrm{P}_{\mathrm{s}}\right)$ is an important property for a film when considering its application in food packaging. The $P_{S}$ values of the fabricated films were evaluated and compared (Table 1). Neat CS film exhibited $\mathrm{P}_{\mathrm{S}} \mathrm{ca} .818 .57 \%$. The presence of CNC considerably decreased the $\mathrm{P}_{\mathrm{S}}$ of the CS film. For example, when $2 \mathrm{wt} . \%$ CNC (cf. CS2) was loaded in the CS matrix, the $P_{s}$ value decreased from $818.57 \%$ to $537.85 \%$. The $P_{s}$ values of the composites further decreased (up to $\mathrm{P}_{\mathrm{S}}$ value ca. $392.85 \%$ ) with increasing $\mathrm{CNC}$ content. This decrease may be dependent on the CNC crystalline nature [55]. Some researchers [31] reasoned that the 3D network of CNC moderated the flexibility of $\mathrm{CS}$ molecular chains by reducing the number of $-\mathrm{OH}$, thereby blocking the infiltrate paths of water molecules and confirming that CNC decreased the water absorbency of CS. Similar observations were previously reported [56-58].

Table 1. Water barrier properties of the samples.

\begin{tabular}{cccccc}
\hline \multirow{2}{*}{ Properties } & \multicolumn{5}{c}{ Samples } \\
\cline { 2 - 5 } & CS0 & CS2 & CS4 & CS6 & CS8 \\
\hline$P_{\mathrm{s}}$ & 818.57 & 537.85 & 436.87 & 418.51 & 392.85 \\
EMC $(\%)$ & 34.17 & 29.33 & 27.54 & 25.81 & 24.27 \\
FWS $(\%)$ & 35.70 & 33.85 & 31.91 & 28.20 & 26.55 \\
CA/o & 89.91 & 101.70 & 105.55 & 113.62 & 118.90 \\
WA & 72.99 & 58.04 & 53.41 & 46.89 & 37.62 \\
WVP & 3.83 & 2.91 & 2.72 & 2.54 & 2.41 \\
\hline
\end{tabular}

\subsection{Equilibrium Moisture Content (EMC)}

The EMC values of CS0, CS2, CS4, CS6, and CS8 films were $34.17 \%, 29.33 \%, 27.54 \%, 25.81 \%$, and $24.27 \%$, respectively. As shown in Table 1, the samples containing CNC (cf. CS2, CS4, CS6, and CS8) showed lower EMC than CS. The decrease in the EMC value could be due to the less availability of free hydroxyl groups of the matrix that participated in hydrogen bonding to CNC. Ojagh et al. [59] 
and Fernandes et al. [60] reported similar results. Furthermore, the EMC results of the samples were $24.27-34.17 \%$ lower than that those (13-18\%) reported by Dehnad et al. [32].

\subsection{Film Water Solubility}

The FWS values of CS0, CS2, CS4, CS6, and CS8 films were 35.70, 33.85, 31.91, 28.20, and 26.55, respectively. As shown in Table 1, the FWS of the samples decreased from 35.70 to 26.55 with increasing CNC loading (0-8 wt.\%). This phenomenon can be explained on the basis of 3D network structure of $\mathrm{CNC}$, which protected the movement of polymers to water, resulting in the reduced FWS of the samples $[58,61]$.

\subsection{Contact Angle (CA) of Nanocomposite Film}

The CA values of CS0, CS2, CS4, CS6, and CS8 films were $89.91^{\circ}, 101.70^{\circ}, 105.55^{\circ}, 113.62^{\circ}$, and $118.90^{\circ}$, respectively. As shown in Table 1, CS0 and CS8 showed the highest hydrophilicity (lowest hydrophobic) and the lowest hydrophilicity (highest hydrophobic) among all of the tested films, respectively. The increase in the contact angle may be due to the hydrophobic nature of $\mathrm{CNC}$, could be beneficial for the water resistance of CS food packaging films. Mao et al. [56] reasoned that CS and CNC joined by hydrogen bonds improved the hydrophobic nature of the composite films. The work of adhesion (WA or $\mathrm{W}_{12}$ ) is the work applied to separate two adjacent phases, namely, 1 and 2. $W_{12}$ depends on the contact angle and surface tension of the liquid and is the energy that is released during wetting. On the basis of Young-Dupree equation:

$$
\mathrm{WA}=\mathrm{W}_{12}=(1+\operatorname{Cos} \theta) \gamma
$$

where $\gamma$ is the surface tension.

$\mathrm{W}_{12}$ can be correlated with the interaction of the filler with the matrix and with the interaction of the filler with a liquid that is comparable with the matrix polymer [62]. The WA values of all samples are shown in Table 1. CS0 and CS8 showed the highest (72.99) and lowest (37.62) work of adhesion, respectively. The decrease in the WA of the composite films could be due to the weak dispersion of CNC in the CS matrix [63].

\subsection{WVP}

Table 1 shows the WVP data of CS0, CS2, CS4, CS6, and CS8 films. The WVP of the composite films $\left(2.91-2.41 \times 10^{-11} \mathrm{gm}^{-1} \mathrm{~s}^{-1} \mathrm{~Pa}^{-1}\right)$ was lower than that of CS $\left(3.83 \times 10^{-11} \mathrm{gm}^{-1} \mathrm{~s}^{-1} \mathrm{~Pa}^{-1}\right)$ film. The reduction can be explained by the physical barrier to the passage of water provided by CNC. Numerous studies $[31,33,64]$ reported a similar behavior. The WVP of mango puree films improved significantly with the addition of CNC [65]. Paralikar, Simonsen, and Lombardi [66] also reported the reduction in the WVP of $\mathrm{PVOH}$ films due to the addition of $10 \%(\mathrm{w} / \mathrm{w}) \mathrm{CNC}$.

\subsection{Opacity and UV Visibility}

The study of opacity governed the features of the transparent food packaging films. Opacity is a type of degree that does not allow light to pass through a material. The lower the opacity is, the higher the amount of light that can pass through the material will be. The opacity data of the reported films are listed in Table 2. Neat CS exhibited an opacity ca. of $0.916 \mathrm{~mm}$, which was evidently lower than that of the composites. All composites (cf. CSO-8) showed evidently higher opacity values due to the high loading of $\mathrm{CNC}$, demonstrating that the composites can evidently hinder light to pass through the film compared with controlled CS. The UV absorbance graphs of CS and its composite with CNC (cf. CSO-8) is presented in Figure 7A. The UV light absorption increases with increasing CNC due to presence of the 3D structure of CNC. Furthermore, CNC blocked UV light, further creating films resistant to UV wavelengths. Zhang et al. [67] found that CNC-reinforced PVC thin film reduced UV absorption. 
Table 2. Physical properties of the samples.

\begin{tabular}{cccccc}
\hline \multirow{2}{*}{ Properties } & \multicolumn{5}{c}{ Samples } \\
\cline { 2 - 6 } & CS0 & CS2 & CS4 & CS6 & CS8 \\
\hline Thickness $(\mathrm{mm})$ & 0.020 & 0.021 & 0.020 & 0.021 & 0.020 \\
Opacity & 0.916 & 4.985 & 5.066 & 5.700 & 11.920 \\
Transparency & 95.08 & 79.22 & 69.81 & 62.32 & 56.11 \\
TS (MPa) & $75.2 \pm 1.6$ & $79.3 \pm 2.6$ & $104.7 \pm 1.3$ & $101.4 \pm 1.8$ & $99.6 \pm 1.5$ \\
YM (MPa) & $1158 \pm 36$ & $1607 \pm 32$ & $2068 \pm 28$ & $1993 \pm 32$ & $1957 \pm 29$ \\
EB (\%) & $21.8 \pm 0.5$ & $16.8 \pm 0.6$ & $9.9 \pm 0.4$ & $9.2 \pm 0.5$ & $8.9 \pm 0.3$ \\
\hline
\end{tabular}
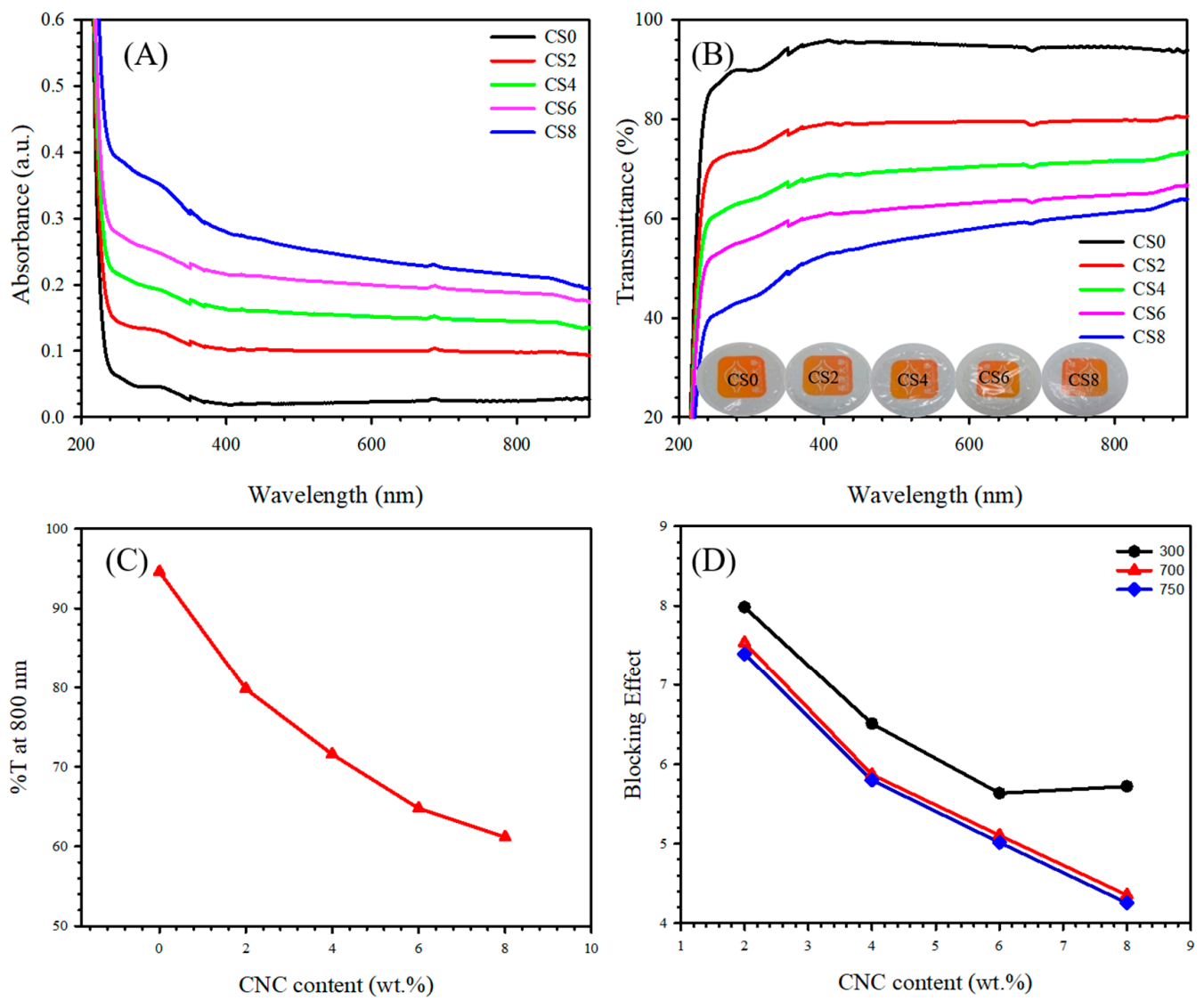

Figure 7. (A) UV absorption curve, (B) UV transmittance curve, (C) optical percentage transmittance $(\% \mathrm{~T})$ of UV at $800 \mathrm{~nm}$, and (D) blocking effect of UV at different wavelengths for CS0, CS2, CS4, CS6, and CS8 films. Inset of Figure (B): digital image of fabricated films.

The OM images presented in Figure 5 demonstrate the surface roughness of CS0, CS2, CS4, CS6, and CS8 films. The difference in the surface nature between CS0 and CS is due to the presence of CNC (cf. CS2, CS4, CS6, and CS8) films. The CS0 films showed more uniform surface than CS containing $\mathrm{CNC}$, and the surface uniformity decreased with increasing CNC content. Furthermore, the improvement in the transmittance of films was ascribed to the increase in the surface smoothness (low roughness) of the film due to the decrease of surface light scattering [68].

The transparency of the CS0, CS2, CS4, CS6, and CS8 films was studied using UV/visible light spectroscopy. Figure 7C presents the transmittance of light at $800 \mathrm{~nm}$. The transmittance of the CS nanocomposite films significantly decreased from $94.62 \%$ to $61.17 \%$ with an increase in the CNC loading (0-8 wt.\%). This result may be due to the agglomeration of CNC in the CS matrix. Li et al. [69] also reported that the transmittance of composite films rapidly decreased from $89 \%$ to $62 \%$ with further 
CNC loading. The digital images of the obtained transparent films are shown in Figure 7B. The order of transparency is as follows:

CS0 > CS2 > CS4 > CS6 > CS8;

$95.08>79.22>69.81>62.32>56.11$.

The transmittance spectra clearly show that the transmittance decreased with increasing CNC content because of light scattering [7]. The blocking effect [70] of CNC for the used films was determined using the following formula:

$$
\text { Beff }=\frac{\text { TCS }- \text { TCNC } / C S}{\text { Percentage of CNC with respect to the CS }}
$$

where $\mathrm{T}_{\mathrm{CS}}$ and $\mathrm{T}_{\mathrm{CNC} / \mathrm{CS}}$ are the transmittance of $\mathrm{CS}$ film and the $\mathrm{CNC} / \mathrm{CS}$ nanocomposites, respectively. Figure 7D shows the $B_{\text {eff }}$ of the CNC at 300, 700, and $750 \mathrm{~nm}$ (UV-B, UV-A, and visible regions, respectively). Based on the results, the addition of CNC conferred CS with high barrier properties, resulting in enhanced UV light resistance.

\subsection{Mechanical Properties}

Enhanced mechanical properties are necessary for edible films developed in the food industry because they can hold integrity during processing, handling, and shipping [71]. Accordingly, the mechanical performance of CS and CNC/CS films with various amounts of CNC loading were evaluated by typical tensile experiments. Values were determined in terms of Young's modulus (YM), tensile strength (TS), and elongation at break (EB). The used films were rectangular with a size of $10 \mathrm{~mm} \times 60 \mathrm{~mm} \times 0.02 \mathrm{~mm}$ for tensile tests. The tensile tests of the CS0, CS2, CS4, CS6, and CS8 films (in accordance with ASTM D638) were conducted at a crosshead speed of $10 \mathrm{~mm} / \mathrm{min}$ by using a Gotech AI-3000 system. The YM, TS, and EB were taken to be the average value of the five tests for each composition. As shown in Table 2, a small amount of CNC loading significantly improved the tensile properties. The TS values of CS2 $(79.3 \pm 2.6 \mathrm{MPa})$, CS4 $(104.7 \pm 1.3 \mathrm{MPa})$, CS6 $(101.4 \pm 1.8 \mathrm{MPa})$, and CS8 $(99.6 \pm 1.5 \mathrm{MPa})$ were higher than those of CS0 (75.2 $\pm 1.6 \mathrm{MPa})$. Thus, the TS values of CS2, CS4, CS6, and CS8 were 5.45\%, 39.23\%, 34.84\%, and 32.45\% higher than that of CS0. The improvement in TS may be due to the strong hydrogen bonding between the CNC and the CS matrix phase [72]. Furthermore, the TS of the films decreased from 104.7 $\pm 1.3 \mathrm{MPa}$ to $101.4 \pm 1.8 \mathrm{MPa}$ when the loading amount of the $\mathrm{CNC}$ was increased from 4 to $6 \mathrm{wt} . \%$. The value further decreased to $99.6 \pm 1.5 \mathrm{MPa}$ with further increase in the loading amount of $\mathrm{CNC}$ at $8 \mathrm{wt} . \%$. This finding may be attributed to the agglomeration of CNC in the CS matrix [73]. Khan et al. also found similar trends [31,58]. Numerous tensile observations $[69,74,75]$ for packaging with low loading of nanofillers in various commercial biopolymer were examined.

The TS of the CS control film $(75.2 \pm 1.6 \mathrm{MPa})$ obtained in this study was similar to that of films in previous reports, such as ca. 72.0 [51], 79 [76], 21.07 [5], 46.50 [34], 85.0 [55], 32.9 [64], and 47.68. $\mathrm{MPa}$ [33]. The TS values of films were comparable to those of plastic-based films, such as films based on LDPE (8-10 MPa), HDPE (19-31 MPa), EVOH (6-19 MPa), PCL (4 MPa), PS (31-49 MPa), PLA (45 MPa), PVC (42-55 MPa), and PP (27-98 MPa) [50]. Li et al. [69] found that the TS of the composite films increased from 85 to $120 \mathrm{MPa}$, with an increase of CNC content from 0 to $15 \mathrm{wt} . \%$. Yu et al. [77] studied that the TS of the PVA/CS biodegradable films with $0.6 \mathrm{wt}$. $\%$ was as high as 44.12 MPa and improved by $45 \%$ through hydrogen bonds between silica and PVA or CS. Barra et al. [6] reported that the loading of ( $50 \mathrm{wt} . \%$ ) rGO in CS matrix is increased by two and six times that for TS and YM, respectively. Some other papers reported less improvement in the TS and EB (\%) of CS on the loading of $\mathrm{Na}^{+} \mathrm{MMT} / \mathrm{CS}$, Cloisite 30B, and silver nanoparticles [64]. 
As presented in Table 2, the YM values of CS2, CS4, CS6, and CS8 were significantly improved by $38.8 \%, 78.6 \%, 72.6 \%$, and $70.0 \%$, respectively, relative to that of CSO. The improved YM values of reinforced CS films may be ascribed to the improved stiffness of the films by the inclusion of CNC. This observation suggests that the added CNC acts as good reinforcing agents to the CS. Hosseini et al. [78] also reported similar results. Tang et al. [79] observed that the CS/gellan gum nanocomposite films with 7\% CNC exhibited increased TS and YM by $80.9 \%$ and $41.7 \%$, respectively, and decreased EB by $53.1 \%$ relative to those of pure CS/gellan gum composite films. Pan et al. [80] observed that after forming the nanocomposite film with (1 wt.\%) GO loading, the YM, TS, and EB are increased by $51 \%, 93 \%$, and $41 \%$, respectively, which are much higher than those of neat CS films. With the addition of only $(0.2 \mathrm{wt} . \%)$ unzipped multiwall carbon nanotube oxides into the CS matrix, the TS and YM are increased from 69.3 to $142.7 \mathrm{MPa}$ and 2.6 to $6.9 \mathrm{GPa}$, showing increases of $105.9 \%$ and $165 \%$, respectively, as reported by Fan et al. [81].

The EB values of CS0, CS2, CS4, CS6, and CS8 were $21.8 \% \pm 0.5 \%, 16.8 \% \pm 0.6 \%, 9.9 \% \pm 0.4 \%$, $9.2 \% \pm 0.5 \%$, and $8.9 \% \pm 0.3 \%$, respectively (Table 2). The EB of the nanocomposite films decreased from $21.8 \% \pm 0.5 \%$ to $8.9 \% \pm 0.3 \%$ when the loading amount of the CNC was increased from 0 to $8 \mathrm{wt} . \%$. This result may be due to the lesser availability of the motion at the interface of filler-polymer [82]. Recently, similar observations were also found by Barra et al. [6]. The EB of the prepared nanocomposites is comparable to those of films based on PS (2-3\%), PVC (20-180\%), and PVDC (10-40\%). On the basis of improved TS and YM of CNC reinforced samples, we could conclude that these films can be used in the packaging industry.

\subsection{Comparison of Obtained Mechanical Performance between the Present Study and Previous Works}

As presented in Table S2, the mechanical behavior of CNC4 was higher than that previously reported [5,30,31,33-35,51,55,60,83] suggesting that CNC/CS films can be used in the food packaging industry.

\subsection{Biodegradability and Stability of the Prepared Films}

The food industry is one of the highest packaging disposal creators; as such, obtaining biodegradable packages for foodstuff is an important requirement to avoid environmental problems. Therefore, researchers have focused on using sustainable biomaterials for food packaging. The biodegradability of food material is well studied by Yabannavar et al. [84]. The word "biodegradable" is used to describe materials that can be degraded by the enzymatic action of living organisms $[85,86]$. A biodegradable material is a good alternative for traditional non-biodegradable materials due to its recycling behavior. Thus, we studied the biodegradability of CS and CNC-reinforced CS. As presented in Figure 8A, the biodegradability of CS thin film increased up to $70.27 \%$ as the burial time increased in the garden soil for 8 days. However, in the case of CNC-reinforced CS films, the rate of degradation decreased due to presence of strong hydrogen bonds between CNC and CS matrix [87]. Therefore, the CNC incorporation in CS matrix decreased the degradation percentage of films by up to $8 \mathrm{wt} . \%$ of $\mathrm{CNC}$.

The stability of prepared films in water is presented in Figure 8B. After dipping in water for 30 days, neat CS film was degraded and broken into small pieces [88]. However, CNC-reinforced CS films showed less degradation and remained almost intact. The obtained results revealed that the prepared CS2, CS4, CS6, and CS8 films showed improved stability. Therefore, we can assume that CNC-reinforced CS films can be used as packing materials in the food industry. 


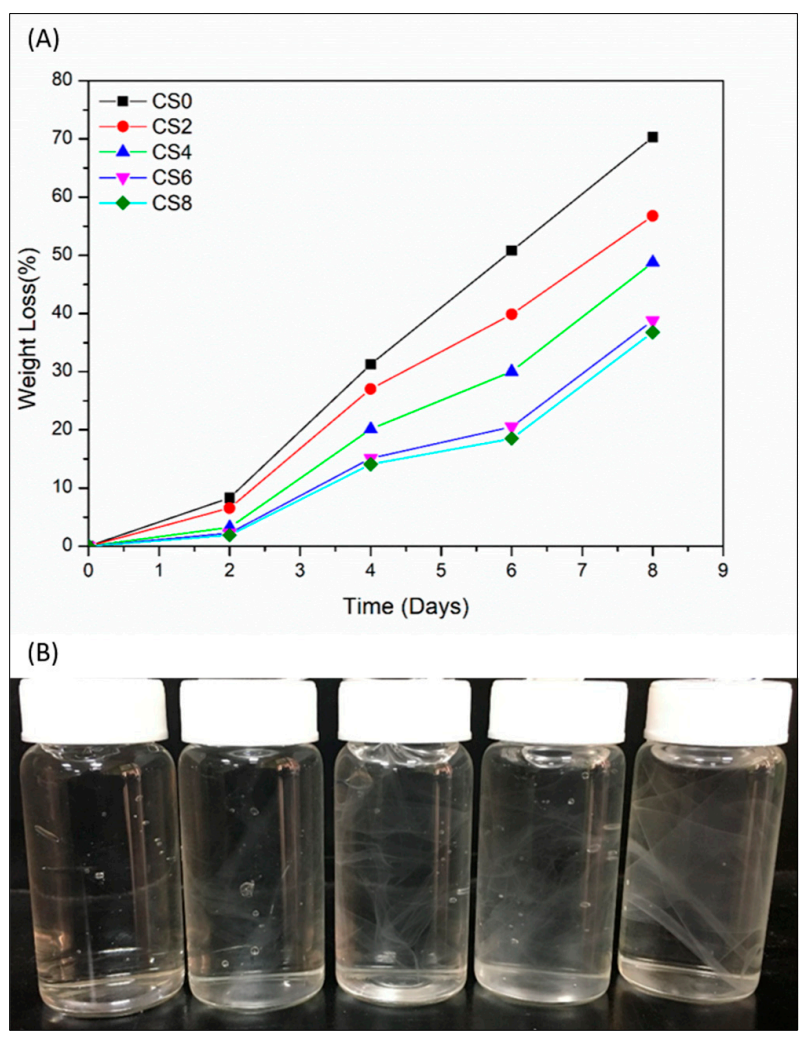

Figure 8. (A) Biodegradability and (B) stability of CS0, CS2, CS4, CS6, and CS8 films.

\section{Discussion}

CNC-reinforced CS-based sustainable biocomposite films with enhanced properties were successfully obtained by mixing CNC and CS through solution casting. The needle-shaped CNC was successfully synthesized from CMC by acid-hydrolysis treatment. The modification of the chemical structure of CNC/CS composite was analyzed by FTIR and XRD studies, revealing the formation of hydrogen bonds between CNC and CS. FESEM and OM images confirmed a dispersion of CNC throughout the CS matrix without remarkable agglomerations. TGA results indicated that chitosan and its composites exhibited almost same thermal stability. In the presence of CNC in the nanocomposites, water and UV barrier properties were also improved. FWS and EMC were reduced by $27 \%$ and $32 \%$, respectively, after incorporation of only $4 \mathrm{wt} . \% \mathrm{CNC}$. The aim of improving UV absorption with the presence of CNC in composites was achieved, and the composites evidently showed lower transmittance compared with control CS. The TS and YM of CS film was improved with the incorporation of $\mathrm{CNC}$, whereas EB decreased with increasing brittleness of the composite films. Moreover, the composites with CNC loading showed lower biodegradation percentage than the control CS due to the presence of strong interaction through H-bonding between CS and CNC. Therefore, CNC/CS bionanocomposite film could be candidates for potential applications in the food packaging field.

Supplementary Materials: The following are available online at http://www.mdpi.com/2073-4360/12/1/202/s1, Table S1: Thermal stability of CMC, CNC, CS0, CS2, CS4, CS6, and CS8 samples, Table S2: Comparison of mechanical properties of CS and its nanocomposites.

Author Contributions: M.Y. did the experimental work, analyzed the results, and wrote the whole manuscript. K.B. assisted the biodegradability test. Y.-H.C. revised the manuscript. F.-C.C. advised experimental techniques. All authors have read and agreed to the published version of the manuscript.

Acknowledgments: The authors thank to Chang Gung Memorial Hospital (CMRPD2J0081/BMRP392) for financial support. The financial support and Post-doctoral fellowship from Ministry of Science and Technology (Taiwan) under contracts MOST 106-2221-E-182-058-MY3 and MOST 108-2811-E-182-500 are appreciated as well. 
Conflicts of Interest: The authors declare no conflict of interest.

\section{References}

1. Laycock, B.; Nikolić, M.; Colwell, J.M.; Gauthier, E.; Halley, P.; Bottle, S.; George, G. Lifetime prediction of biodegradable polymers. Prog. Polym. Sci. 2017, 71, 144-189. [CrossRef]

2. Rhim, J.W.; Park, H.M.; Ha, C.S. Bio-nanocomposites for food packaging applications. Prog. Polym. Sci. 2013, 38, 1629-1652. [CrossRef]

3. Rochman, C.M.; Browne, M.A.; Halpern, B.S.; Hentschel, B.T.; Hoh, E.; Karapanagioti, H.K.; Rios-Mendoza, L.M.; Teh, S.; Thompson, R.C. Classify plastic waste as hazardous. Nature 2013, 494, 169. [CrossRef]

4. Kanmani, P.; Rhim, J.W. Physical, mechanical and antimicrobial properties of gelatin based active nanocomposite films containing AgNPs and nanoclay. Food Hydrocoll. 2014, 35, 644-652. [CrossRef]

5. Salari, M.; Sowti Khiabani, M.; Rezaei Mokarram, R.; Ghanbarzadeh, B.; Samadi Kafil, H. Development and evaluation of chitosan based active nanocomposite films containing bacterial cellulose nanocrystals and silver nanoparticles. Food Hydrocoll. 2018, 84, 414-423. [CrossRef]

6. Barra, A.; Ferreira, N.M.; Martins, M.A.; Lazar, O.; Pantazi, A.; Jderu, A.A.; Neumayer, S.M.; Rodriguezd, B.J.; Enăchescu, M.; Ferreira, P.; et al. Eco-friendly preparation of electrically conductive chitosan-Reduced graphene oxide flexible bionanocomposites for food packaging and biological applications. Compos. Sci. Technol. 2019, 173, 53-60. [CrossRef]

7. Yadav, M.; Chiu, F.C. Cellulose nanocrystals reinforced k-carrageenan based UV resistant transparent bionanocomposite films for sustainable packaging applications. Carbohydr. Polym. 2019, 211, 181-194. [CrossRef]

8. Yadav, M.; Ahmad, S.; Chiu, F.C. Graphene oxide dispersed polyvinyl chloride/alkyd green nanocomposite film: Processing and physico-mechanical properties. J. Ind. Eng. Chem. 2018, 68, 246-256. [CrossRef]

9. Roy, S.; Shankar, S.; Rhim, J.W. Melanin-mediated synthesis of silver nanoparticle and its use for the preparation of carrageenan-based antibacterial films. Food Hydrocoll. 2019, 88, 237-246. [CrossRef]

10. Kim, K.W.; Min, B.J.; Kim, Y.T.; Kimmel, R.M.; Cooksey, K.; Park, S.I. Antimicrobial activity against foodborne pathogens of chitosan biopolymer films of different molecular weights. LWT Food Sci. Technol. 2011, 44, 565-569. [CrossRef]

11. Sreekumar, S.; Goycoolea, F.M.; Moerschbacher, B.M.; Rivera-Rodriguez, G.R. Parameters influencing the size of chitosan-TPP nano- and microparticles. Sci. Rep. 2018, 8, 4695. [CrossRef] [PubMed]

12. Rinaudo, M. Chitin and chitosan: Properties and applications. Prog. Polym. Sci. 2006, 31, 603-632. [CrossRef]

13. Chang, W.; Liu, F.; Sharif, H.R.; Huang, Z.; Goff, H.D.; Zhong, F. Preparation of chitosan films by neutralization for improving their preservation effects on chilled meat. Food Hydrocoll. 2019, 90, 50-61. [CrossRef]

14. Amirabad, L.M.; Jonoobi, M.; Mousavi, N.S.; Oksman, K.; Kaboorani, A.; Yousefi, H. Improved antifungal activity and stability of chitosan nanofibers using cellulose nanocrystal on banknote papers. Carbohydr. Polym. 2018, 189, 229-237. [CrossRef] [PubMed]

15. Bellich, B.; D'Agostino, I.; Semeraro, S.; Gamini, A.; Cesàro, A. "The Good, the Bad and the Ugly" of Chitosans. Mar. Drugs 2016, 14, 99. [CrossRef] [PubMed]

16. Croisier, F.; Jérôme, C. Chitosan-based biomaterials for tissue engineering. Eur. Polym. J. 2013, 49, 780-792. [CrossRef]

17. Elieh-Ali-Komi, D.; Hamblin, M.R. Chitin and Chitosan: Production and Application of Versatile Biomedical Nanomaterials. Int. J. Adv. Res. 2016, 4, 411-427.

18. Muzzarelli, R.; Tarsi, R.; Filippini, O.; Giovanetti, E.; Biagini, G.; Varaldo, P.E. Antimicrobial properties of N-carboxybutyl chitosan. Antimicrob. Agents Chemother. 1990, 34, 2019-2023. [CrossRef]

19. Tran, C.D.; Duri, S.; Delneri, A.; Franko, M. Chitosan-cellulose composite materials: Preparation, Characterization and application for removal of microcystin. J. Hazard. Mater. 2013, 252-253, 355-366. [CrossRef]

20. Ravi Kumar, M.N.V. A review of chitin and chitosan applications. React. Funct. Polym. 2000, 46, 1-27. [CrossRef] 
21. Wang, W.; Jung, J.; Zhao, Y. Chitosan-cellulose nanocrystal microencapsulation to improve encapsulation efficiency and stability of entrapped fruit anthocyanins. Carbohydr. Polym. 2017, 157, 1246-1253. [CrossRef] [PubMed]

22. Zhang, X.; Liu, Y.; Yong, H.; Qin, Y.; Liu, J.; Liu, J. Development of multifunctional food packaging films based on chitosan, $\mathrm{TiO}_{2}$ nanoparticles and anthocyanin-rich black plum peel extract. Food Hydrocoll. 2019, 94, 80-92. [CrossRef]

23. Khan, R.A.; Salmieri, S.; Dussault, D.; Uribe-Calderon, J.; Kamal, M.R.; Safrany, A.; Lacroix, M. Production and Properties of Nanocellulose-Reinforced Methylcellulose-Based Biodegradable Films. J. Agric. Food Chem. 2010, 58, 7878-7885. [CrossRef] [PubMed]

24. Brinchi, L.; Cotana, F.; Fortunati, E.; Kenny, J.M. Production of nanocrystalline cellulose from lignocellulosic biomass: Technology and applications. Carbohydr. Polym. 2013, 94, 154-169. [CrossRef]

25. Moon, R.J.; Martini, A.; Nairn, J.; Simonsen, J.; Youngblood, J. Cellulose nanomaterials review: Structure, properties and nanocomposites. Chem. Soc. Rev. 2011, 40, 3941-3994. [CrossRef]

26. Revol, J.F.; Bradford, H.; Giasson, J.; Marchessault, R.H.; Gray, D.G. Helicoidal self-ordering of cellulose microfibrils in aqueous suspension. Int. J. Biol. Macromol. 1992, 14, 170-172. [CrossRef]

27. Araki, J.; Wada, M.; Kuga, S.; Okano, T. Flow properties of microcrystalline cellulose sus-pension prepared by acid treatment of native cellulose. Colloids Surf. A Physicochem. Eng. Asp. 1998, 142, 75-82. [CrossRef]

28. Geng, S.; Wei, J.; Aitomäki, Y.; Noël, M.; Oksman, K. Well-dispersed cellulose nanocrystals in hydrophobic polymers by in situ polymerization for synthesizing highly reinforced bio-nanocomposites. Nanoscale 2018, 10, 11797-11807. [CrossRef]

29. Ma, X.; Lv, M.; Anderson, D.P.; Chang, P.R. Natural polysaccharide composites based on modified cellulose spheres and plasticized chitosan matrix. Food Hydrocoll. 2017, 66, 276-285. [CrossRef]

30. Mujtaba, M.; Salaberria, A.M.; Andres, M.A.; Kaya, M.; Gunyakti, A.; Labidi, J. Utilization of flax (Linum usitatissimum) cellulose nanocrystals as reinforcing material for chitosan films. Int. J. Biol. Macromol. 2017, 104, 944-952. [CrossRef]

31. Khan, A.; Khan, R.A.; Salmieri, S.; Tien, C.L.; Riedl, B.; Bouchard, J.; Chauve, G.; Tan, V.; Kamal, M.R.; Lacroix, M. Mechanical and barrier properties of nanocrystalline cellulose reinforced chitosan based nanocomposite films. Carbohydr. Polym. 2012, 90, 1601-1608. [CrossRef] [PubMed]

32. Dehnad, D.; Djomeh, Z.E.; Mirzaei, H.; Jafari, S.M.; Dadashi, S. Optimization of physical and mechanical properties for chitosan-nanocellulose biocomposites. Carbohydr. Polym. 2014, 105, 222-228. [CrossRef] [PubMed]

33. Azeredo, H.M.; Mattoso, L.H.; Avena-Bustillos, R.J.A.; Filho, G.C.; Munford, M.L.; Wood, D.; McHugh, T.H. Nanocellulose reinforced chitosan composite films as affected by nanofiller loading \& plasticizer content. J. Food Sci. 2010, 75, 19-28.

34. Wu, T.; Farnood, R.; O'Kelly, K.; Chen, B. Mechanical behavior of transparent nanofibrillar cellulose-chitosan nanocomposite films in dry and wet conditions. J. Mech. Behav. Biomed. 2014, 32, 279-286. [CrossRef]

35. Borysiak, S.; Grzabka-Zasadzińska, A. Influence of the polymorphism of cellulose on the formation of nanocrystals and their application in chitosan/nanocellulose composites. J. Appl. Polym. Sci. 2016, 133, 1-9. [CrossRef]

36. Yadav, M.; Liu, Y.K.; Chiu, F.C. Fabrication of Cellulose Nanocrystal/Silver/Alginate Bionanocomposite Films with Enhanced Mechanical and Barrier Properties for Food Packaging Application. Nanomaterials 2019, 9, 1523. [CrossRef]

37. Segal, L.; Creely, J.J.; Martin, A.E.; Conrad, C.M. An empirical method for estimating the degree of crystallinity of native cellulose using X-ray diffractometer. Text. Res. J. 1959, 29, 786-794. [CrossRef]

38. Orsuwan, A.; Shankar, S.; Wang, L.F.; Sothornvit, R.; Rhim, J.W. Preparation of antimicrobial agar/banana powder blend films reinforced with silver nanoparticles. Food Hydrocoll. 2016, 60, 476-485. [CrossRef]

39. Noshirvani, N.; Ghanbarzadeh, B.; Fasihi, H.; Almasi, H. Starch-PVA nanocomposite Film Incorporated with Cellulose Nanocrystals and MMT: A Comparative Study. Int. J. Food Eng. 2016, 12, 37-48. [CrossRef]

40. Martucci, J.F.; Ruseckaite, R.A. Biodegradation of three-layer laminate films based on gelatin under indoor soil conditions. Polym. Degrad. Stab. 2009, 94, 1307-1313. [CrossRef]

41. Li, Q.; Renneckar, S. Supramolecular structure characterization of molecularly thin cellulose I nanoparticles. Biomacromolecules 2011, 12, 650-659. [CrossRef] 
42. Wang, H.; Roman, M. Formation and properties of chitosan cellulose nanocrystal polyelectrolyte macro ion complexes for drug delivery applications. Biomacromolecules 2011, 12, 1585-1593. [CrossRef]

43. Nikonenko, N.A.; Buslov, D.K.; Sushko, N.I.; Zhbankov, R.G. Spectroscopic manifestation of stretching vibrations of glycosidic linkage in polysaccharides. J. Mol. Struct. 2005, 752, 20-24. [CrossRef]

44. Lu, P.; Hsieh, Y.L. Preparation and properties of cellulose nanocrystals: Rods, spheres, and network. Carbohyd. Polym. 2010, 82, 329-336. [CrossRef]

45. Popescu, M.-C.; Dogaru, B.-I.; Sun, D.; Stoleru, E.; Simionescu, B.C. Structural and sorption properties of bio-nanocomposite films based on K-carrageenan and cellulose nanocrystals. Int. J. Biol. Macromol. 2019, 135, 462-471. [CrossRef]

46. Sakurai, K.; Takagi, M.; Takahashi, T. Crystal structure of chitosan. I. Unit cell parameters. Sen-i Gakkaishi 1984, 40, 246-253. [CrossRef]

47. Hejri, Z.; Seifkordi, A.A.; Ahmadpour, A.; Zebarjad, S.M.; Maskooki, A. Biodegradable starch/poly(vinyl alcohol) film reinforced with titanium dioxide nanoparticles. Int. J. Min. Met. Mater. 2013, 20, 1001-1011. [CrossRef]

48. Kang, X.; Kuga, S.; Wang, C.; Zhao, Y.; Wu, M.; Huang, Y. Green preparation of cellulose nanocrystal and its application. ACS Sustain. Chem. Eng. 2018, 6, 2954-2960. [CrossRef]

49. Garcia, M.D.S.; Hilliou, L.; Lagaron, J.M. Morphology and Water Barrier Properties of Nanobiocomposites of k/i-Hybrid Carrageenan and Cellulose Nanowhiskers. J. Agric. Food Chem. 2010, 58, 12847-12857. [CrossRef]

50. Otoni, C.G.; Avena-Bustillos, R.J.; Azeredo, H.M.C.; Lorevice, M.V.; Moura, M.R.; Mattoso, L.H.C.; McHugh, T.H. Recent Advances on Edible Films Based on Fruits and Vegetables-A Review. Compr. Rev. Food Sci. F 2017, 16, 1151-1169. [CrossRef]

51. Bonardd, S.; Robles, E.; Barandiaran, I.; Saldias, C.; Leiva, A.; Kortaberria, G. Biocomposites with increased dielectric constant based on chitosan and nitrile-modified cellulose nanocrystals. Carbohydr. Polym. 2018, 199, 20-30. [CrossRef]

52. Grząbka-Zasadzińska, A.; Amietszajew, T.; Borysiak, S. Thermal and mechanical properties of chitosan nanocomposites with cellulose modified in ionic liquids. J. Therm. Anal. Calorim. 2017, 130, 143-154. [CrossRef]

53. Wanjun, T.; Cunxin, W.; Donghua, C. Kinetic studies on the pyrolysis of chitin and chitosan. Polym. Degrad. Stab. 2005, 87, 389-394. [CrossRef]

54. Zawadzki, J.; Kaczmarek, H. Thermal treatment of chitosan in various conditions. Carbohydr. Polym. 2010, 80, 394-400. [CrossRef]

55. Li, Q.; Zhou, J.; Zhang, L. Structure and Properties of the Nanocomposite Films of Chitosan Reinforced with Cellulose Whiskers. J. Polym. Sci. Part B Polym. Phys. 2009, 47, 1069-1077. [CrossRef]

56. Mao, H.; Wei, C.; Gong, Y.; Wang, S.; Ding, W. Mechanical and Water-Resistant Properties of Eco-Friendly Chitosan Membrane Reinforced with Cellulose Nanocrystals. Polymers 2019, 11, 166. [CrossRef]

57. Svagan, A.J.; Hedenqvist, M.S.; Berglund, L. Reduced water vapor sorption in cellulose nanocomposites with starch matrix. Compos. Sci. Technol. 2009, 69, 500-506. [CrossRef]

58. Sanuja, S.; Agalya, A.; Umapathy, M.J. Synthesis and characterization of zinc oxide-neem oil-chitosan bionanocomposite for food packaging application. Int. J. Biol. Macromol. 2015, 74, 76-84. [CrossRef]

59. Ojagh, S.M.; Rezaei, M.; Razavi, S.H.; Hosseini, S.M.H. Development and evaluation of a novel biodegradable film made from chitosan and cinnamon essential oil with low affinity toward water. Food Chem. 2010, 122, 161-166. [CrossRef]

60. Fernandes, S.C.M.; Oliveira, L.; Freire, C.S.R.; Silvestre, A.J.D.; Neto, C.P.; Gandini, A.; Desbrieres, J. Novel transparent nanocomposite films based on chitosan and bacterial cellulose. Green Chem. 2009, 11, 2023-2029. [CrossRef]

61. Oleyaei, S.A.; Zahedi, Y.; Ghanbarzadeh, B.; Moayedi, A.A. Modification of physicochemical and thermal properties of starch films by incorporation of $\mathrm{TiO}_{2}$ nanoparticles. Int. J. Biol. Macromol. 2016, 89, $256-264$. [CrossRef]

62. Jose, T.; George, S.C.; Maya, M.G.; Thomas, S. Functionalized MWCNT and PVA Nanocomposite Membranes for Dielectric and Pervaporation Applications. J. Chem. Eng. Proc. Technol. 2015, 6, 1000233.

63. Thomas, S.P.; Thomas, S.; Abraham, R.; Bandyopadhyay, S. Polystyrene/calcium phosphate nanocomposites: Contact angle studies based on water and methylene iodide. Express Polym. Lett. 2008, 2, 528-538. [CrossRef] 
64. Rhim, J.W.; Hong, S.I.; Park, H.M.; Ng, P.K.W. Preparation and characterization of chitosan-based nanocomposite films with antimicrobial activity. J. Agric. Food Chem. 2006, 54, 5814-5822. [CrossRef]

65. Azeredo, H.M.C.; Mattoso, L.H.C.; Wood, D.; Williams, T.G.; Bustillos, R.J.A.; McHugh, T.H. Nanocomposite edible films from mango puree reinforced with cellulose nanofibers. J. Food Sci. 2009, 74, 31-35. [CrossRef]

66. Paralikar, S.A.; Simonsen, J.; Lombardi, J. Poly(vinyl alcohol)/cellulose nanocrystal barrier membranes. J. Membrane Sci. 2008, 320, 248-258. [CrossRef]

67. Zhang, Z.; Sebe, G.; Wang, X.; Tam, K.C. UV-Absorbing Cellulose Nanocrystals as Functional Reinforcing Fillers in Poly(vinyl chloride) Films. ACS Appl. Nano Mater. 2018, 1, 632-641. [CrossRef]

68. Qing, Y.; Cai, Z.; Wu, Y.; Yao, C.; Wu, Q.; Li, X. Facile preparation of optically transparent and hydrophobic cellulose nanofibril composite films. Ind. Crops Prod. 2015, 77, 13-20. [CrossRef]

69. Li, W.; Xu, Z.; Chen, L.; Shan, M.; Tian, X.; Yang, C.; Lv, H.; Qian, X. A facile method to produce graphene oxide-g-poly(L-lactic acid) as an promising reinforcement for PLLA nanocomposites. Chem. Eng. J. 2014, 237, 291-299. [CrossRef]

70. Castillo, L.; Lopez, O.; Lopez, C.; Zaritzky, N.; Garcia, M.A.; Barbosa, S.; Villar, M. Thermoplastic starch films reinforced with talc nanoparticles. Carbohydr. Polym. 2013, 95, 664-674. [CrossRef]

71. Sothornvit, R.; Rodsamran, P. Effect of a mango film on quality of whole and minimally processed mangoes. Postharvest Biol. Tec. 2008, 47, 407-415. [CrossRef]

72. Huq, T.; Salmieri, S.; Khan, A.; Khan, R.A.; Tien, C.L.; Riedl, B.; Fraschini, C.; Bouchard, J.; Uribe-Calderon, J.; Kamal, M.R.; et al. Nanocrystalline cellulose (NCC) reinforced alginate based biodegradable nanocomposite film. Carbohydr. Polym. 2012, 90, 1757-1763. [CrossRef]

73. Dorigato, A.; Dzenis, Y.; Pegoretti, A. Filler aggregation as a reinforcement mechanism in polymer nanocomposites. Mech. Mater. 2013, 61, 79-90. [CrossRef]

74. Ionita, M.; Pandele, M.A.; Iovu, H. Sodium alginate/graphene oxide composite films with enhanced thermal and mechanical properties. Carbohydr. Polym. 2013, 94, 339-344. [CrossRef]

75. Shen, Y.; Jing, T.; Ren, W.; Zhang, J.; Jiang, Z.G.; Yu, Z.Z.; Dasari, A. Chemical and thermal reduction of graphene oxide and its electrically conductive polylactic acid nanocomposites. Compos. Sci. Technol. 2012, 72, 1430-1435. [CrossRef]

76. Khan, A.; Gallah, H.; Riedl, B.; Bouchard, J.; Safrany, A.; Lacroix, M. Genipin cross-linked antimicrobial nanocomposite films and gamma irradiation to prevent the surface growth of bacteria in fresh meats. Innov. Food Sci. Emerg. Technol. 2016, 35, 96-102. [CrossRef]

77. Yu, Z.; Li, B.; Chu, J.; Zhang, P. Silica in situ enhanced PVA/chitosan biodegradable films for food packages. Carbohydr. Polym. 2018, 184, 214-220. [CrossRef]

78. Hosseini, S.F.; Rezaei, M.; Zandi, M.; Farahmandghavi, F. Fabrication of bio-nanocomposite films based on fish gelatin reinforced with chitosan nanoparticles. Food Hydrocoll. 2015, 44, 172-182. [CrossRef]

79. Tang, Y.; Zhang, X.; Zhao, R.; Guo, D.; Zhang, J. Preparation and properties of chitosan/guar gum/nanocrystalline cellulose nanocomposite films. Carbohydr. Polym. 2018, 197, 128-136. [CrossRef]

80. Pan, Y.; Wu, T.; Bao, H.; Li, L. Green fabrication of chitosan films reinforced with parallel aligned graphene oxide. Carbohydr. Polym. 2011, 831, 908-915. [CrossRef]

81. Fan, J.; Shi, Z.; Ge, Y.; Wang, Y.; Wang, J.; Yin, J. Mechanical reinforcement of chitosan using unzipped multiwalled carbon nanotube oxides. Polymer 2012, 53, 657-664. [CrossRef]

82. Wang, S.; Song, C.; Chen, G.; Gu, T.; Liu, J.; Zhang, B.; Takeuchi, S. Characteristics and biodegradation properties of poly (3-hydroxybutyrate-co-3-hydroxyvalerate)/organophilic montmorillonite (PHBV/OMMT) nanocomposite. Polym. Degrad. Stab. 2005, 87, 69-76. [CrossRef]

83. Pereda, M.; Dufresne, A.; Aranguren, M.I.; Marcovich, N.E. Polyelectrolyte films based on chitosan/olive oil and reinforced with cellulose nanocrystals. Carbohydr. Polym. 2014, 101, 1018-1026. [CrossRef] [PubMed]

84. Yabannavar, A.; Bartha, R. Biodegradability of some food packaging materials in soil. Soil Biol. Biochem. 1993, 25, 1469-1475. [CrossRef]

85. Avella, M.; Vlieger, J.J.D.; Errico, M.E.; Fischer, S.; Vacca, P.; Volpe, M.G. Biodegradable starch/clay nanocomposite films for food packaging applications. Food Chem. 2005, 93, 467-474. [CrossRef]

86. Doi, Y.; Fukuda, K. (Eds.) Biodegradable Plastics and Polymers; Elsevier: Amsterdam, The Netherlands, 1994; pp. 479-497. 
87. Deepa, B.; Abraham, E.; Pothan, L.A.; Cordeiro, N.; Faria, M.; Thomas, S. Biodegradable Nanocomposite Films Based on Sodium Alginate and Cellulose Nanofibrils. Materials 2016, 9, 50. [CrossRef]

88. Han, D.; Yan, L.; Chen, W.; Li, W. Preparation of chitosan/graphene oxide composite film with enhanced mechanical strength in the wet state. Carbohy. Polym. 2011, 83, 653-658. [CrossRef]

(C) 2020 by the authors. Licensee MDPI, Basel, Switzerland. This article is an open access article distributed under the terms and conditions of the Creative Commons Attribution (CC BY) license (http://creativecommons.org/licenses/by/4.0/). 